Original article

\title{
Assessment of risk factors and predictors for spontaneous pre-term birth in a South Indian antenatal cohort
}

\author{
Chythra R. Rao ${ }^{\mathrm{a}, *}$, Parvati Bhat ${ }^{\mathrm{b}}$, Vandana $\mathrm{KE}^{\mathrm{c}}$, Veena Kamath ${ }^{\mathrm{a}}$, Asha Kamath ${ }^{\mathrm{a}}$, \\ Dinesh Nayak $^{\mathrm{d}}$, Revathi P. Shenoy ${ }^{\mathrm{e}}$, Shashikala K. Bhat ${ }^{\mathrm{b}}$ \\ a Department of Community Medicine, Kasturba Medical College, Manipal University, Manipal, 576104, Karnataka State, India \\ ${ }^{\mathrm{b}}$ Department of $\mathrm{OBG}$ at Dr TMA Pai Hospital Udupi, Melaka Manipal Medical College, Manipal University, Karnataka State, India \\ c Department of Microbiology, Kasturba Medical College, Manipal University, Manipal, 576104, Karnataka State, India \\ d Department of Paediatrics, at Dr TMA Pai Hospital Udupi, Melaka Manipal Medical College, Manipal University, Karnataka State, India \\ e Department of Biochemistry, Kasturba Medical College, Manipal University, Manipal, 576104, Karnataka State, India
}

\section{A R T I C L E IN F O}

\section{Article history:}

Received 7 June 2017

Received in revised form 19 July 2017

Accepted 22 July 2017

Available online 24 July 2017

\section{Keywords:}

Preterm births

Risk factors

Oligohydramnios

IUGR

Cohort study

\begin{abstract}
A B S T R A C T
Objective: To assess incidence of spontaneous preterm births and determine biochemical and obstetric risk factors for spontaneous pre-term births in a cohort of antenatal women visiting a secondary care hospital.

Methods: A prospective cohort study was designed to include 1420 pregnant women coming for antenatal care at a secondary care hospital. The cohort was followed throughout pregnancy and relevant history, obstetric and ultrasonographic examination and biochemical investigations was carried out in 2nd (2024 weeks period of gestation) and 3rd trimester (28-32 weeks period of gestation). Outcome of delivery was noted for all the subjects.

Results: A total of 1133 women were recruited. Among the 1071 respondents, 11 had abortions, 93.1\% delivered at term while $5.9 \%$ had preterm deliveries. Preterm deliveries were noted among $6.5 \%$ women with short stature, $13.3 \%$ with cervical length $<2.5 \mathrm{cms}$ and $5.2 \%$ among women with anaemia. Statistically significant association was noted between Oligohydramnios, IUGR and preterm births. Salivary estriol was lower in women who had preterm births as compared to term births.

Conclusions: The incidence of preterm births (5.9\%) was low in the present cohort. Oligohydramnios and Intrauterine Growth Retardation (IUGR) were identified as significant risk factors for preterm births. Conventional risk factors like short cervix, short stature and biochemical inflammatory markers were not identified as predictors of prematurity. Lower levels of salivary estriol identified among women at risk of preterm births demonstrates the utility of the test as a non-invasive investigation for early identification of preterm births.
\end{abstract}

(c) 2017 INDIACLEN. Published by Elsevier, a division of RELX India, Pvt. Ltd. All rights reserved.

\section{Introduction}

For much of the 20th century, preterm birth, defined as birth at less than 37 completed weeks of gestation, was viewed as an unpredictable and inevitable fact of life. Medical efforts thus focused on ameliorating the consequences of prematurity rather than preventing its occurrence. ${ }^{1}$ Pre-term birth (PTB) is a major determinant of neonatal mortality, morbidity and childhood disability and remains one of the most serious problems in obstetrics. Despite major preventive efforts, the incidence of PTB has remained constant at about $5-10 \%$ of live births in most

\footnotetext{
* Corresponding author.

E-mail address: chythra.raj@manipal.edu (C.R. Rao).
}

countries over the past two decades. In $75 \%$ of PTB cases no obvious causes have been established, but several etiological risk factors have been speculated. Non-obstetric risk factors include: poor socioeconomic status, maternal malnutrition, maternal age of $<20$ and $>35$ years, heavy manual work and cigarette smoking. ${ }^{1-4}$ Obstetric risk factors associated with PTB include: cervical incompetence, short cervical length, multiple gestations, short birth intervals, abortion, pre-labor premature rupture of membrane (PPROM) and previous PTB. ${ }^{5-7}$ Current knowledge indicates that iron deficiency anemia in pregnancy is a risk factor for preterm delivery and subsequent low birth weight. ${ }^{8-10}$ In addition, risks for preterm birth have been documented to increase with elevated levels of biomarkers, ${ }^{11}$ high levels of hCG, maternal age $<20$ years, two or more previous miscarriages, ${ }^{12}$ and reduced salivary estriol levels. ${ }^{13}$ 
Overall incidence of preterm labor is reported to be $6-15 \%$ and $4-50 \%$ of these occur spontaneously, whereas $25 \%$ occur following preterm pre-labor rupture of membranes (PPROM). ${ }^{14}$ India, despite having highest number of births and neonatal deaths in the world, still has paucity of data on preterm births and the risk factors thereof, coupled with diversity in geography, availability and utilization of health services. Hence the current study was designed to estimate the incidence of spontaneous preterm births and identify the biochemical risk factors like inflammatory markers namely $\mathrm{C}$ - reactive protein (CRP), Inter Leukin -4 (IL4), Tumor Necrosis Factor alpha (TNF- $\alpha$ ) which might be suggestive of chorioamnionitis predisposing to preterm labour; assess levels of triple markers namely Estriol, $\alpha 1$ - Feto protein (AFP) and Human Chorionic Gonadotrophin $\beta$ sub unit ( $\beta$ hcG); estimate progesterone levels which ensure the sustenance of pregnancy and ascertain the role of obstetric risk factors like short cervix in the causation of spontaneous preterm births in a secondary care hospital of coastal Karnataka. In addition, the study proposed to evaluate role of salivary estriol (E3) in detecting increased risk of spontaneous preterm labour. The study focused on spontaneous preterm births, hence documented risk factors for indicated pre term births were primarily excluded at recruitment.

\section{Methods}

\subsection{Study setting and population}

A prospective cohort study was carried out in the Department of Obstetrics and Gynaecology (OBG) at a secondary care hospital, in collaboration with Departments of Paediatrics, Biochemistry and Community Medicine of a Medical College, over a period of three years. The study population included pregnant women of gestation period between 8-16 weeks, in the age group of 18-35 years coming for routine ante-natal check-up to the obstetrics outpatient department (OPD) of the secondary care hospital and willing to participate in the study. Those with past history of epilepsy and HIV and those with past obstetric complications like placenta praevia, abruption, cervical encirclage, uterine fibroid, uterine anomaly and multiple pregnancies (twin and triplet pregnancies) were excluded, as these conditions could lead to iatrogenic preterm deliveries.

Sample size calculation was based on short cervix as a parameter representing risk for preterm births in the cohort. The sample size was calculated anticipating a sensitivity of $56 \%$ for cervical length as a predictor of pre term labour, ${ }^{15}$ with a relative precision of $3 \%$ at $5 \%$ level of significance, 1207 women needed to be enrolled for the study. Accounting for a drop out of $10 \%$ and exclusion of $5 \%$ of the pregnant women due to pregnancy related complications in the follow up period, the sample to be recruited in the cohort was 1420 .

\subsection{Data collection methodology}

Permission was obtained from the institutional ethical committee review board (IEC: $\mathbf{3 2} / \mathbf{2 0 1 1}$ ) before initiation of the study. All the pregnant women found to be eligible and willing to participate in the study were enrolled during their first visit to the OBG OPD after obtaining written informed consent. The design has been outlined in Fig. 1. The cohort was followed throughout pregnancy and relevant history, obstetric and ultrasonographic examination and biochemical investigations was carried out for which five $\mathrm{ml}$ of blood was drawn in 2nd (20-24 weeks period of gestation) and 3rd trimester (28-32 weeks period of gestation), for all the subjects. The outcome of delivery was recorded. Routine hospital tests, done in the first trimester was obtained from the records of the subjects. Post natal assessment of gestational age

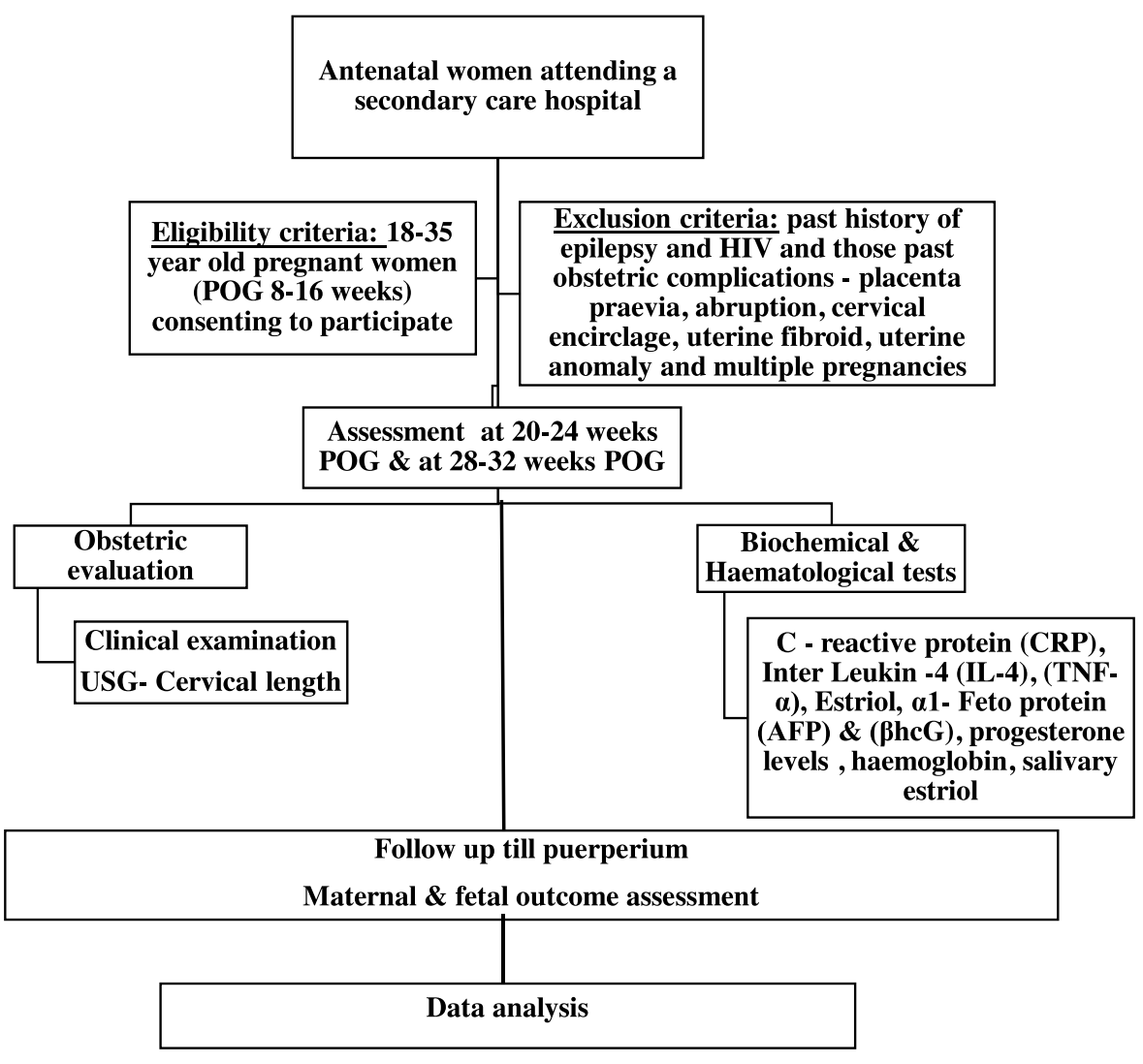

Fig. 1. Flow diagram depicting the Study design. 
was done by the paeditrician, to rule out false labelling of pre-term births. All the subjects were followed through pregnancy, labour, delivery and puerperium.

The socio-demographic, obstetric, medical history, anthropometric measurements and relevant laboratory results like hemoglobin, routine urine analysis, VDRL, HIV serology etc was documented in the study proforma, by the study staff. Gestational age was assessed by Naegele's rule (last menstrual period), clinical examination and confirmed by ultrasonography. Clinical examination was done by qualified obstetrician to assess the health of mother and fetus. Ultrasound examination was done to assess cervical length during 2 nd trimester. Women having short cervical length $(\leq 2.5 \mathrm{~cm})$ as assessed by transvaginal scan at 20-24 weeks, were considered to be at higher risk of pre-term labour. ${ }^{5}$

\subsection{Biochemical estimations}

Estimation of haemoglobin was done using the cyanmethhaemoglobin method. Women with haemoglobin level of $<11 \mathrm{~g} / \mathrm{dL}$ were considered to be anaemic and were treated accordingly. The Diagnostic Automation Estriol ELISA kit was used for the quantitative determination of Estriol. ELISA kit was used for quantitative determination of inflammatory markers such as, Tumor Necrosis Factor alpha (TNF- $\alpha$ ) and Inter Leukin -4 (IL-4).

For the in vitro quantitative determination of $\alpha 1$ - Feto protein (AFP), Human Chorionic Gonadotrophin $\beta$ sub unit ( $\beta$ hcG), progesterone in human serum and plasma, the electrochemiluminesence immunoassay ELCIA was used on Elecsys and cobase immunoassay analysers. $\mathrm{C}$ - reactive protein (CRP) is a member of the class of acute-phase reactants, as its levels rise dramatically during inflammatory processes occurring in the body. CRP was determined by immunoturbidimetric method.

\subsubsection{Salivary estriol (E3)}

Subjects were instructed to collect a sample of unstimulated saliva any time between 9 am and 8 pm because no significant variation in E3 levels has been found between those hours. Each subject was asked to rinse her mouth with water, wait for 10 minutes, and then drool two $\mathrm{mL}$ of saliva into a plastic cup. Subjects were asked to avoid eating, drinking, smoking, tooth brushing, mouth washing, or gum chewing for one hour before collection. ${ }^{16}$
A single, positive (at or above $2.1 \mathrm{ng} / \mathrm{mL}$ ) salivary E3 test was considered for samples collected during the third trimester, while a threshold of $1.4 \mathrm{ng} / \mathrm{mL}$, was used for the 2 nd trimester samples. ${ }^{16}$.

\subsection{Data analysis}

Data was entered and analyzed using Statistical Package for Social Sciences (SPSS) version 15.0 Data has been summarized as proportions and risk estimated as Relative Risk (RR). Mean and standard deviation (SD), median and interquartile range (IQR) were used to summarize the biochemical parameters. Strength of association was determined using relative risk for the risk factors of preterm labour. Chi-square test was used for univariate analysis. A $\mathrm{p}$ value of less than 0.05 was considered to be statistically significant.

\section{Results}

For the study period of three years, 1133 consenting, eligible antenatal women were recruited in I trimester. Of the 1133 women, the total number of respondents were 1060 (93.5\%), 11 abortion cases constituted $1 \%$ and 62 women (5.5\%) were non-respondents. Excluding the abortions, outcome details were available for total of 1060 women, of whom 997 (93.1\%) delivered at term and 63 (5.9\%) delivered preterm. Hence, the incidence of spontaneous preterm births in the prospective cohort was $5.9 \%$. Study recruitment and outcomes are outlined in Fig. 2.

Among the recruited women, 670 (59\%) were primi gravida, 362 (32\%) were second gravida, 90 (7.9\%) were third gravida, seven women were pregnant for the fourth time while it was the fifth and sixth pregnancy for two mothers each.

Over half of the study subjects belonged to the age group of 2530 years as depicted in Table 1 and nearly $75 \%$ of the women were educated up to class 10-12. The mean age of the cohort was 27 years and on average the duration of married life was two to three years. Haemoglobin was in the normal range for the antenatal women during all the trimesters, in spite of the haemodilution during pregnancy. The total counts (WBC) were also in the specified range ruling out possibility of infections. Preterm deliveries were seen among 10 women (6.5\%) with height $<150 \mathrm{cms}$, four woman (13.3\%) with cervical length $<2.5 \mathrm{cms}$ and 9 (5.2\%) women with anaemia (Haemoglobin $<11 \mathrm{~g} / \mathrm{dL}$ ). Less

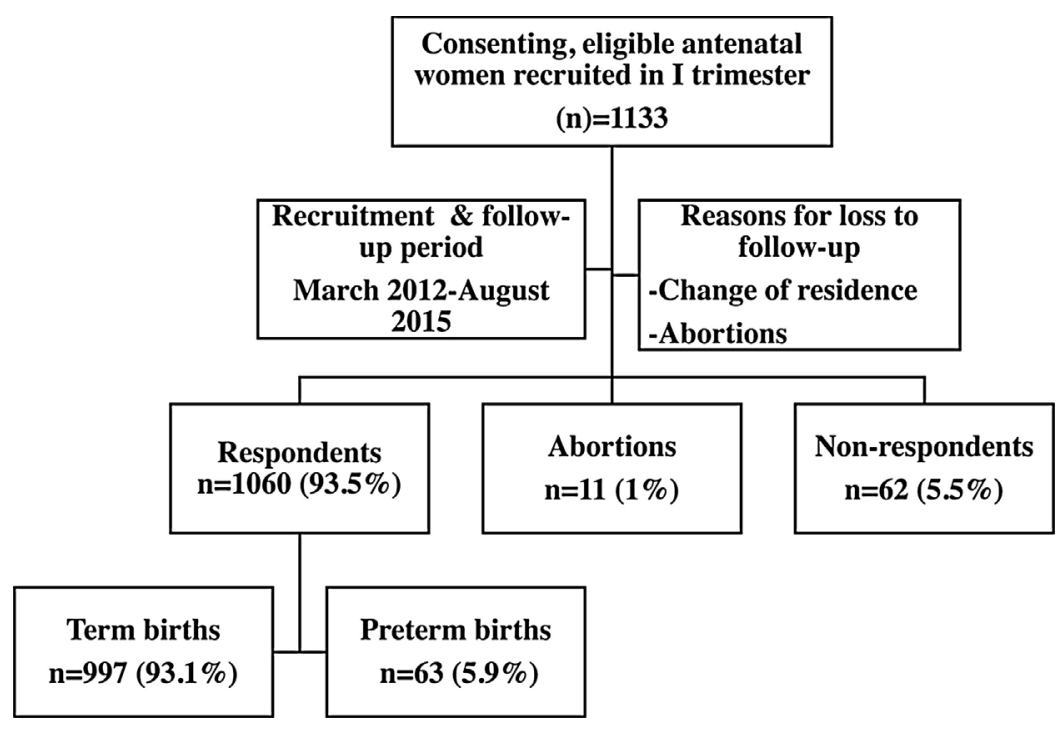

Fig. 2. Flow chart depicting recruitment and follow up of participants. 
Table 1

Socio-demographic characteristics of the antenatal women $(\mathrm{n}=1133)$.

\begin{tabular}{lll}
\hline Variables & $\mathrm{n}$ & $\%$ \\
\hline Age group (Years) & & \\
$18-24$ & 285 & 25.2 \\
$25-30$ & 641 & 56.6 \\
$>31$ & 207 & 18.2 \\
Religion & & \\
Hindu & 1054 & 93.0 \\
Christian & 55 & 4.9 \\
Muslim & 24 & 2.1 \\
& & \\
Education status & & 0.3 \\
Illiterate & 03 & 7.0 \\
Primary \& secondary & 79 & 74.9 \\
SSLC \& PUC & 849 & 17.8 \\
Graduation \& above & 202 & \\
& & \\
Monthly Income (Rupees) & & 17.1 \\
$\leq 10,000$ & 193 & 73.5 \\
10,001-30,000 & 833 & 9.4 \\
$\geq 30,001$ & 107 &
\end{tabular}

than five percent of women had Pregnancy induced hypertension and Gestational diabetes.

The median values for inflammatory markers, suggestive of any ongoing overt or covert infections like C-reactive protein, TNFalpha and IL- 4 were comparable among both the term and preterm category. Progesterone (median value 188.9 among preterm births $\mathrm{v} / \mathrm{s} 184$ among term births) is required for the sustenance of pregnancy and there was no difference in the levels in both the categories. The median value for Salivary Estriol in 3rd trimester was significantly lower among the preterm births (246.3, against median value of 533.5 among term births) and this merits further evaluation.

Significant risk factors associated with preterm births are described in Table 2. The risk of Oligohydramnios detected in 2nd trimester was 11 times as compared to a fourfold risk in 3rd trimester. Similarly Intrauterine Growth Retardation (IUGR) was associated with a 6-7 times higher risk of preterm births and these associations were found to be statistically significant. The association between preterm births and pregnancy induced hypertension also showed a risk of 2.75 times.

Table 3 summarizes the risk factors for preterm births, wherein significant risk of association was noted for presence of any fetal conditions which included IUGR, oligohydramnios and polyhydramnios and threatened preterm in 3rd trimester. This association was also identified to be statistically significant by multivariate logistic regression analysis.

Cox regression analysis identified only IUGR in the 3rd trimester (Adjusted risk: 2.17; 95\% CI: 1.10, 4.27) and threatened preterm (Adjusted risk: 31.59 ; 95\% CI: 18.89, 52.85) in the 3rd trimester as significant risk factors among all the maternal and fetal attributes.

\section{Discussion}

An estimated 15 million babies are born too early every year; which amounts to more than one in 10 babies. Almost one million children die each year due to complications of preterm birth. Globally, prematurity is the leading cause of death in children under the age of five. And in almost all countries with reliable data, preterm birth rates are increasing. ${ }^{17}$ Despite decades of research, we are no closer to finding answers in terms of prediction and hence prevention of preterm labour. ${ }^{18}$

Documented risk factors like multiple pregnancy, placenta praevia and precious pregnancy/bad obstetric history are usually associated with indicated preterm births and hence, these were excluded from the present study as the study primarily aimed to identify non-traditional risk factors for spontaneous preterm births.

The causes for preterm births could be broadly classified as being Maternal or Fetal in origin. Maternal risk factors include low literacy levels, unbooked cases, fewer antenatal visits, extremes of age, low body mass index, tobacco and alcohol use, maternal comorbidities or complications of pregnancy like over distension of uterus due to twins or polyhydramnios, short cervical length and genitourinary infections. ${ }^{19}$ The fetal risk factors includes placental abnormalities like low lying placenta, intrauterine growth retardation, threatened preterm, premature rupture of membranes and fetal fibronectin levels. ${ }^{20}$ Health system factors comprises of poor access to health facilities, lack of specialized care and affordability issues.

Table 2

Medical conditions influencing preterm births (Total births $=1060$ ).

\begin{tabular}{|c|c|c|c|c|c|}
\hline Variable categories & Preterm birth [n=63] n (\%) & Term birth [n=997] n (\%) & Exact 'p' value & Relative risk & $95 \% \mathrm{CI}$ \\
\hline \multicolumn{6}{|c|}{ Oligohydramnios in $2^{\text {nd }}$ trimester } \\
\hline Present $(n=03)$ & $02(66.7)$ & $01(33.3)$ & 0.010 & 11.55 & $5.00-26.66$ \\
\hline Absent $(n=1057)$ & $61(5.8)$ & $996(94.2)$ & & & \\
\hline \multicolumn{6}{|c|}{ Oligohydramnios in $3^{\text {rd }}$ trimester } \\
\hline Present $(n=66)$ & $13(19.7)$ & $53(80.3)$ & $<\mathbf{0 . 0 0 1}$ & 3.91 & $2.24-6.83$ \\
\hline Absent $(n=994)$ & $50(5.0)$ & $944(95.0)$ & & & \\
\hline \multicolumn{6}{|l|}{ IUGR in $2^{\text {nd }}$ trimester } \\
\hline Present $(n=09)$ & $04(44.4)$ & $05(55.6)$ & 0.001 & 7.91 & 3.66-17.12 \\
\hline Absent $(n=1051)$ & $59(5.6)$ & $992(94.4)$ & & & \\
\hline \multicolumn{6}{|l|}{ IUGR in $3^{\text {rd }}$ trimester } \\
\hline Present $(n=44)$ & $13(29.5)$ & $31(70.5)$ & $<0.001$ & 6.00 & $3.53-10.20$ \\
\hline Absent $(n=1016)$ & $50(4.9)$ & $966(95.1)$ & & & \\
\hline \multicolumn{6}{|l|}{ Gestational diabetes } \\
\hline Present $(n=41)$ & $05(12.2)$ & $36(87.8)$ & 0.090 & 2.14 & $0.90-5.05$ \\
\hline Absent $(n=1019)$ & $58(5.7)$ & $961(94.3)$ & & & \\
\hline \multicolumn{6}{|c|}{ Pregnancy induced hypertension } \\
\hline Present $(n=39)$ & $06(15.4)$ & $33(84.6)$ & 0.024 & 2.75 & $1.26-6.00$ \\
\hline Absent $(n=1021)$ & $57(5.6)$ & $964(94.4)$ & & & \\
\hline
\end{tabular}


Table 3

Traditional risk factors associated with preterm births.

\begin{tabular}{|c|c|c|c|c|c|}
\hline Variables & Number & $\begin{array}{l}\text { Preterm births } \\
(\mathrm{N}=63) \mathrm{n}(\%)\end{array}$ & $\begin{array}{l}\text { Term births } \\
(\mathrm{N}=997) \mathrm{n}(\%)\end{array}$ & Relative risk & $95 \% \mathrm{CI}$ \\
\hline \multicolumn{6}{|c|}{ Cervical length (cms) } \\
\hline$<2.5$ & 30 & $4(13.3)$ & $26(86.7)$ & 2.33 & $0.90-5.99$ \\
\hline$\geq 2.5$ & 1030 & $59(5.7)$ & $971(94.3)$ & & \\
\hline \multicolumn{6}{|c|}{ Haemoglobin $(\mathrm{g} / \mathrm{dL})$} \\
\hline$<10$ & 31 & $01(3.2)$ & $0(6.8)$ & 0.54 & $0.07-3.73$ \\
\hline$\geq 10$ & 1029 & $62(6.0)$ & $967(94.0)$ & & \\
\hline \multicolumn{6}{|c|}{ Height (cms) } \\
\hline$<145$ & 28 & $01(3.6)$ & $27(96.4)$ & 0.59 & $0.08-4.13$ \\
\hline$>145$ & 1032 & $62(6.0)$ & $970(94.0)$ & & \\
\hline \multicolumn{6}{|c|}{ BMI at first visit $\left(\mathrm{kg} / \mathrm{m}^{2}\right)$} \\
\hline$>25$ & 136 & $11(8.1)$ & $125(91.9)$ & 1.43 & $0.76-2.68$ \\
\hline$<25$ & 924 & $52(5.6)$ & $872(94.4)$ & & \\
\hline \multicolumn{6}{|c|}{ Gravida status } \\
\hline Primi & 625 & $36(5.8)$ & $589(94.2)$ & 0.92 & $0.57-1.50$ \\
\hline Multi & 435 & $27(6.2)$ & $408(93.8)$ & & \\
\hline \multicolumn{6}{|c|}{ Previous $\mathrm{H} / \mathrm{O}$ abortion } \\
\hline Yes & 112 & $07(6.3)$ & $105(93.8)$ & 1.05 & $0.49-2.26$ \\
\hline No & 948 & $56(5.9)$ & $892(94.1)$ & & \\
\hline \multicolumn{6}{|c|}{ Maternal disease } \\
\hline Yes & 41 & $5(12.2)$ & $36(87.8)$ & 2.14 & $0.90-5.05$ \\
\hline No & 1019 & $58(5.7)$ & $961(94.3)$ & & \\
\hline \multicolumn{6}{|c|}{ Threatened preterm in 3rd trimester ${ }^{*}$} \\
\hline Yes & 31 & $25(80.6)$ & $06(19.4)$ & 21.83 & 15.28-31.19 \\
\hline No & 1029 & $38(3.7)$ & $991(96.3)$ & & \\
\hline \multicolumn{6}{|c|}{ Fetal conditions ${ }^{*}$} \\
\hline Yes & 44 & $13(29.5)$ & $31(70.5)$ & 6.00 & $3.53-10.20$ \\
\hline No & 1016 & $50(4.9)$ & $966(95.1)$ & & \\
\hline
\end{tabular}

* identified as significant variables in multiple logistic regression analysis.

In the present cohort maternal and health system factors were not identified as statistically significant variables. The District level data for 2014-2015 for Udupi district, situated in the coastal belt of Karnataka highlights the reasons for the same. The literacy rate of Udupi district is $88.2 \%$ for males and $75.2 \%$ for females. Antenatal coverage and institutional deliveries is universal for the native population, the exception being the migrant population. Birth rate is $12.2 \%$, death rate is $4.4 \%$, infant death rate is 7.3 per 1000 live births and only 10 maternal deaths were reported for 2014-2015. These statistics are far above the national average and comparable to most of the indicators of developed countries.

Surprisingly in the present cohort, almost all of the significant risk factors identified have been of fetal origin. Intrauterine growth retardation, oligohydramnios, premature rupture of membranes, threatened preterm in 3rd trimester have emerged as significant risk factors.

A prospective international multicentre cohort study among 3184 women, reported only 156 (4.9\%) to have spontaneous preterm births. As per the authors, the ability to predict PTB in healthy nulliparous women using clinical characteristics, including cervical length was only modest. ${ }^{21} \mathrm{~A}$ recent publication from a tertiary care hospital in Delhi ${ }^{18}$ also reports results on similar lines, the rate of preterm birth being $5 \%$ among low risk women and that traditional risk factors like cervical length and inflammatory markers like interleukins etc were not identified as good markers for preterm births. This is in stark contrast to WHO, in which India ranks first for the greatest number of preterm births. ${ }^{17}$

IUGR was associated with a 6-7 times higher risk of preterm births and these associations were found to be statistically significant. The association between preterm births and pregnancy induced hypertension also showed a risk of 2.75 times. A European case control study also identified growth restriction as a risk factor for preterm births. ${ }^{22} \mathrm{~A}$ case control study in Iran reported a prevalence rate of preterm birth was $5.1 \%$ with a four times odds of oligohydramnios being associated with preterm births, similar to the present study. ${ }^{23}$ A retrospective study from a rural tertiary care center reported prevalent causes of prematurity to be anemia, PIH, GDM, oligohydromnios, multiple pregnancies, antepartum hemorrhage, polyhydramnios, fetal distress and cervical incompetence. $^{24}$

Early identification and active intervention for Oligohydramnios and IUGR is the norm at the study set-up. Oligohydramnios is being effectively and routinely treated by usage of L-arginine supplements by the obstetricians. Nutritional supplements and improved dietary habits are suggested to the mothers for addressing IUGR; the benefits of which have been documented in the literature. ${ }^{25-30}$ In addition, medical conditions like anaemia, pregnancy induced hypertension and gestational diabetes mellitus identified during the course of the follow up were promptly managed. These active interventions have contributed to the lower incidence of preterm births identified in the study.

The prospective cohort study intended to identify hitherto unidentified obstetric, biochemical and haematological risk factors for spontaneous preterm births among antenatal attendees of a secondary care hospital. Low attrition rates in a hospital set-up was an affirmative finding. Documented risk factors like anaemia, inflammatory markers suggestive of infection and short cervical length were not identified as significant predictors in the study. The investigators also acknowledge that the recruitment was short of calculated sample size and attribute it to the low birth rate of 
16.8/1000 population for the district; the cultural practice of going to mother's place for delivery; good health care delivery system, commendable female literacy and 100\% institutional deliveries. But nevertheless, every attempt was made to include and ensure complete follow-up of all the eligible antenatal women visiting the secondary care hospital. The authors opine that in the light of results where maternal factors played minimal role as causes of prematurity, the focus needs to shift towards fetal factors like intrauterine growth retardation and oligohydramnios which are easily identifiable during early pregnancy and amenable to effective interventions.

\section{Conclusions}

The incidence of preterm births was 5.9\% in the present cohort. Among the fetal risk factors contributing to prematurity, Oligohydramnios and Intrauterine Growth Retardation (IUGR) were more often associated with preterm births. Traditional risk factors like short cervix, short stature, biochemical inflammatory markers and hematological parameters were not identified as predictors for preterm birth. Salivary estriol was lower in women who had preterm births as compared to women with term. Hence, salivary estriol could be recommended as a novel, non-invasive investigation in the routine antenatal panel for early identification of women at risk of preterm births.

\section{Source(s) of support}

This work was supported by Indian Council of Medical Research- (IRIS ID No. 2011-01660, RFC No.: RHN/Ad-hoc/33/ 2011-2012)

The role of the supporting agency was only for providing funding for the conduct of the study and has no role in analysis and interpretation of data; in the writing of the report; and in the decision to submit the article for publication. There are no funds available to cover the publication costs.

\section{Conflict of interest}

None.

\section{Author's contribution}

Concepts- Chythra R. Rao, Parvati Bhat, Vandana KE, Veena Kamath, Asha Kamath, Dinesh Nayak, Revathi P. Shenoy, Shashikala K. Bhat

Design- Chythra R. Rao, Parvati Bhat, Vandana KE, Veena Kamath, Asha Kamath, Dinesh Nayak, Revathi P. Shenoy, Shashikala K. Bhat

Definition of intellectual content-Chythra R. Rao, Vandana KE, Veena Kamath, Asha Kamath, Dinesh Nayak, Revathi P. Shenoy, Shashikala K. Bhat

Literarure search- Chythra R. Rao, Vandana KE, Revathi P. Shenoy

Clinical studies- Chythra R. Rao, Parvati Bhat, Vandana KE, Revathi P. Shenoy

Data acquisition- Chythra R. Rao, Parvati Bhat, Vandana KE, Revathi P. Shenoy, Shashikala K. Bhat

Statistical analysis- Chythra R. Rao, Vandana KE, Asha Kamath Manuscript preperation-Chythra R. Rao, Parvati Bhat, Vandana

KE, Veena Kamath, Asha Kamath

Manuscript editing- Chythra R. Rao, Parvati Bhat

Manuscript review- Chythra R. Rao, Parvati Bhat, Vandana KE, Veena Kamath, Asha Kamath, Dinesh Nayak, Revathi P. Shenoy, Shashikala K. Bhat

Guarantor- Chythra R. Rao

\section{References}

[1]. Muglia LJ, Katz M. The Enigma of Spontaneous Preterm Birth. N Engl J Med. 2010;362:529-535.

[2]. Al-Dabbagh SA, Al-Taee WY. Risk factors for pre-term birth in Iraq: a casecontrol study. BMC Pregnancy Childbirth. 2006;6:1310.1186/1471-2393-6-13.

[3]. Green NS, Damus K, Simpson JL, Iams J, Reece A, Hobel CJ, et al. Research agenda for preterm birth: Recommendations from the March of Dimes. Am J Obstet Gynecol. 2005;193:626-635.

[4]. Silveira MF, Victora CG, Barros AJD, Santos IS, Matijasevich A, Barros FC. Determinants of preterm birth: Pelotas, Rio Grande do Sul State, Brazil, 2004 birth cohort. Cad. Saúde Pública, Rio de Janeiro, 2010; 26: 185-194. Available from URL: http:// www.scielosp.org/pdf/csp/v26n1/19.pdf

[5]. Hebbar S, Samjhana K. Role of Mid-Trimester Transvaginal Cervical Ultrasound in Prediction of Preterm Delivery. Med J Malaysia. 2006;61:307-311.

[6]. Kore SJ, Parikh MP, Lakhotia S, Kulkarni V, Ambiye VR. Prediction of risk of preterm delivery by cervical assessment by transvaginal ultrasonography. $J$ Obstet Gynecol India. 2009;59:131-135.

[7]. Gomez R, Romero R, Medina L, Nien JK, Chaiworapongsa T, Carstens M, et al. Cervicovaginal fibronectin improves the prediction of preterm delivery based on sonographic cervical length in patients with preterm uterine contractions and intact membranes. Am J Obste Gynecol. 2005;192:350-359.

[8]. Allen LH. Biological Mechanisms That Might Underlie Iron's Effects on Fetal Growth and Preterm Birth. J Nutr. 2001;131:581S-589S.

[9]. Allen LH. Anemia and iron deficiency: effects on pregnancy outcome. Am J Clin Nutr. 2000;71(suppl):1280S-1284S.

[10]. Zhang Q, Ananth CV, Li Z, Smulian JC. Maternal anaemia and preterm birth: a prospective cohort study. Int J. Epidemiol. 2009;38:1380-1389.

[11]. Jelliffe-Pawlowski LL, Baer RJ, Currier RJ. Second trimester serum predictors of preterm birth in a population-based sample of low-risk pregnancies. Prenat Diagn. 2010;30:727-733.

[12]. Smith GCS, Shah I, White IR, Pell JP, Crossley JA, Dobbie R. Maternal and biochemical predictors of spontaneous preterm birth among nulliparous women: a systematic analysis in relation to the degree of prematurity. Int. J Epidemiol. 2006;35:1169-1177.

[13]. Darne J, McGarrigle HHG, Lachelin GCL. Saliva oestriol, oestradiol, oestrone and progesterone levels in pregnancy: Spontaneous labour at term is preceded by rise in the saliva oestriol/progesterone ratio. $\mathrm{Br} J$ Obstet Gynaecol. 1987;94:227-235.

[14]. Chandraharan E, Arulkumaran S. Recent advances in management of preterm labor. J Obstet Gynecol India. 2005;55:118-124.

[15]. Benardis P, Daskalakis G. Screening for preterm labor. Donald School J. Ultrasound Obstet Gynaecol. 2008;2(1):37-47.

[16]. Heine RP, McGregor JA, Goodwin TM, Artal R, Hayashi RH, Robertson PA, et al. Serial Salivary Estriol to Detect an Increased Risk of Preterm Birth. Obstet Gynecol. 2000;96:490-497.

[17]. WHO preterm births: Available from URL: http://www.who.int/mediacentre/ factsheets/fs363/en/ Accessed 20 April 2017

[18]. Tripathi R, Tyagi S, Singh N, Mala YM, Singh C, Bhalla P, et al. Can Preterm Labour Be Predicted in Low Risk Pregnancies? Role of Clinical, Sonographic, and Biochemical Markers. J Pregnancy. 2014;. Article ID 623269 http://dx.doi. org/10.1155/2014/623269.

[19]. Iams JD. Preterm birth. In: Gabbe SG, Niebyl JF, Simpson JL, eds. Obstetrics: Normal and Problem Pregnancies. 3rd ed. New York, NY: Churchill Livingstone; 1996:743-820.

[20]. Goldenberg RL, Culhane JF, Iams JD, Romero R. Preterm Birth 1. Epidemiology and causes of preterm birth. Lancet. 2008;371:75-84.

[21]. Dekker GA, Lee SY, North RA, McCowan LM, Simpson NAB, Roberts CT. Risk Factors for Preterm Birth in an International Prospective Cohort of Nulliparous Women. PLoS ONE. 2012;7(7):e3915410.1371/journal.pone.0039154.

[22]. Zeitlin J, Ancel PY, Saurel-Cubizolles MJ, Papiernik E. The relationship between intrauterine growth restriction and preterm delivery: an empirical approach using data from a European case-control study. Br J Obstet Gynaecol. 2000;107:750-758.

[23]. Alijahan R, Hazrati S, Mirzarahimi M, Pourfarzi F. Ahmadi Hadi P Prevalence and risk factors associated with preterm birth in Ardabil, Iran. Iran J Reprod Med. 2014;12(1):47-56.

[24]. Kuppusamy N, Vidhyadevi A. Prevalence of Preterm Admissions and the Risk Factors of Preterm Labor in Rural Medical College Hospital. Int J Sci Stud. 2016;4 (9):125-128. 
[25]. Hebbar S, Rai L, Adiga P. Maternal hydration and L-arginine supplementation improves liquor volume in patients with decreased liquor and prolongs pregnancy. Med J DY Patil Univ. 2014;7:429-434.

[26]. Soni A, Garg S, Patel K, Patel Z. Role of L-Arginine in Oligohydramnios. J Obstet Gynecol India. 2016;66(S1):S279-S28310.1007/s13224-016-0853-7.

[27]. Sreedharan R, Jajoo S. Effect of L-arginine on amniotic fluid index in oligohydramnios. Int J Reprod Contracept Obstet Gynecol. 2013;2:808210.5455/2320-1770.ijrcog20130214.
[28]. Rai P, Kumari G, Kumari K, Rawat R, Swaroop N. Evaluation of role of amino acid infusion in cases of intrauterine growth restriction: Our experience. Indian J Obstet Gynecol Res. 2016;3(4):366-36910.18231/2394-2754.2016.0015.

[29]. Brown LD, Green AS, Limesand SW, Rozance PJ. Maternal amino acid supplementation for intrauterine growth restriction. Front Biosci (Schol Ed). 2011;3:428-444.

[30]. Abu-Saad K. Fraser D: Maternal Nutrition and Birth Outcomes. Epidemiol Rev. 2010;32:5-25. 